2:15pm - 2:30pm

MD3

\title{
Mg Diffusion Formed P-type GaN
}

\author{
Jia-Liang. Yen, Fuh-Shyang, and Ying-Jay Yang \\ Department of Electrical Engineering, National Taiwan University, Taipei, Taiwan.
}

Fax: 886-2-23638247

E-mail: yjyang@cc.ee.ntu.edu.tw

In the development of $\mathrm{GaN}$ and related nitride compound, using $\mathrm{Mg}$ doping to form a p-type GaN plays a critical role for making green-to-blue light emitting devices. ${ }^{1}$ Despite of the progress in the in-situ $\mathrm{Mg}$ doping process, ${ }^{2}$ the conventional post-growth doping techniques, such as the diffusion process to achieve higher hole concentration for better p-type ohmic contact or device operation, haven't been successfully demonstrated yet. Also due to the lack of reliable process the diffusion properties of $\mathrm{Mg}$, which may affect the device structure and operation, still remain unknown. In this paper, we report on $\mathrm{Mg}$ diffusion into unintentionally doped n-type GaN resulting in p-type GaN formation.

The experiment is briefly described as the following: First, using a thermal evaporator a $\mathrm{Mg} / \mathrm{Au}$ film was deposited on GaN/sapphire samples with 2-4 $\mu \mathrm{m}$ thick unintentionally doped n-type GaN grown by MOCVD, then the sample was sealed in a vacuumed quarts ampoule and put into a 900-1000 ${ }^{\circ} \mathrm{C}$ furnace for $\mathrm{Mg}$ diffusion. After diffusion the sample was removed from the ampoule and the deposited $\mathrm{Mg} / \mathrm{Au}$ was etched off by a solution of $1 \mathrm{HNO}_{3}$ $3 \mathrm{HCl}$. Finally the samples were put in RTA for thermal annealing at $850-1050{ }^{\circ} \mathrm{C}$ for $5-20$ minutes to activate the diffused $\mathrm{Mg}$. The $\mathrm{Mg}$ diffusion profile of a processed sample has been measured by SIMS and is shown in Figure 1 . The profile with double fronts agrees with the previous results of $\mathrm{Mg}$ diffused in $\mathrm{Al}_{\mathrm{x}} \mathrm{Ga}_{1-x} \mathrm{As}$, ${ }^{3}$ which can be well explaincd by the kick-out mechanism. ${ }^{4}$ The Hall measurement data indicate that all the diffused and annealed samples consistently show p-type conductivity with hole concentrations in the range of $10^{16} / \mathrm{cm}^{3}-10^{17} / \mathrm{cm}^{3}$ and mobility of $<$ $100 \mathrm{~cm}^{2}-V s$. In Figure 2 the variable tempcrature Hall measurement data show that the activation energy Ea (derived from the dash line) of the diffused $\mathrm{Mg}$ around the room temperature is $166 \mathrm{meV}$, which is consistent with that of the in-situ doped Mg. ${ }^{5}$ Typical low temperature PLs of samples with and without diffusion are shown in Figure 3. Both spectra show extonic emission peaks at $3.47 \mathrm{eV}$ which is attributed to the neutral donor bound extonic recombination, ${ }^{6}$ and a "yellow" emission band around $2.2 \mathrm{eV}$ which is possibly due to the defect related emission and commonly observed in the other GaN. One can note that only the diffused GaN shows a strong $\mathrm{Mg}$ related "blue" emission band with first peak at $3.27 \mathrm{eV}$ and followed by two $\mathrm{LO}$ phonon replica with $\sim 90 \mathrm{meV}$ separation, which is attributed to a donor-acceptor(DA) transition and agrees well with the previous result of p-type $\mathrm{Mg}$-doped $\mathrm{GaN}^{7}$

\section{References:}

1. S. Nakamura, M. Senoh, and T. Mukai, Appl. Phys. Lett. 62, 2390(1993)

2. H. Amano, M. Kitoh, K. Hiramatsu, and I. Akasaki, Jpn. J. Appl. Phys. 28, L2112(1989).

3. S. Mukai, Y. Kaneko, T. Nukui, M. Mori, M. Watanabe, H. Itoh, and H. Yajima, Jpn. Appl. Phys

28, L1(1989).

4. S. Yu, T. Y. Tan, and U. Gosele, J. Appl. Phys. 69, 3547(1991).

5. I. Akasaki, H. Amano, M. Kitoh, and K. Hiramatsu, J. Lumin. 48, 666(1991).

6. G. D. Chen, M. Smith, J. Y. Lin, and H. X. Jiang, Appl. Phys. Lett. 67, 1653(1995).

7. H. Amano, M. Kitoh, K. Hiramatsu, and I. Akasaki, J. Electrochem. Soc. 137, 1639(1990). 


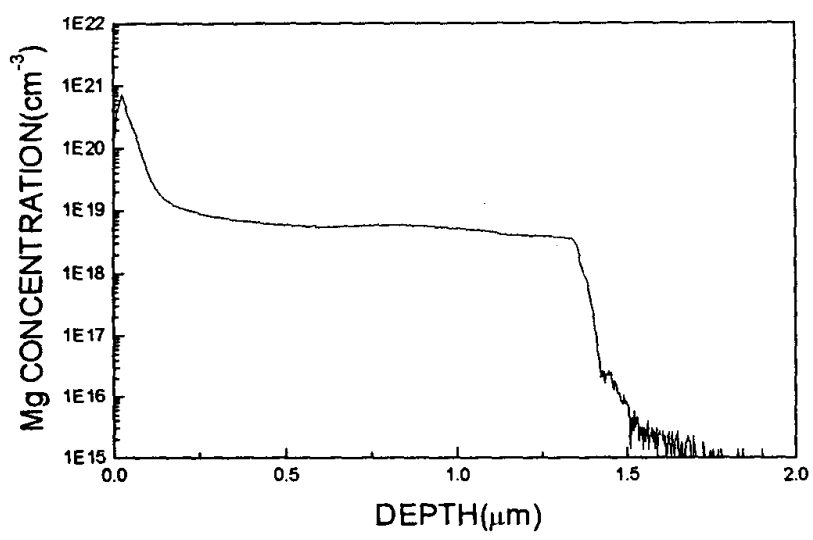

Figure 1. SIMS profile for Mg diffusion in GaN at $900^{\circ} \mathrm{C}$ for $24 \mathrm{hrs}$.

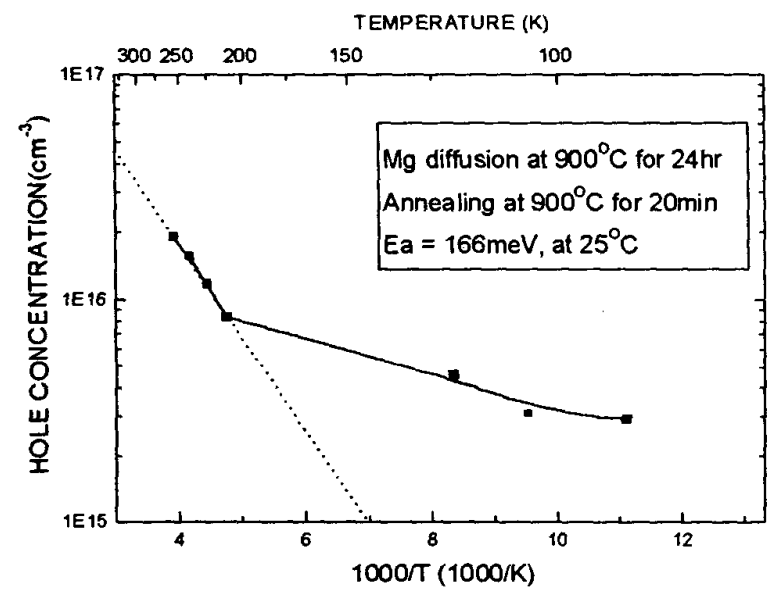

Figure 2. The hole concentrations as function of temperature from the variable temperature Hall measurement. The activation energy $\mathrm{Ea}$ of $\mathrm{Mg}$ derived from the dash line is $166 \mathrm{meV}$.

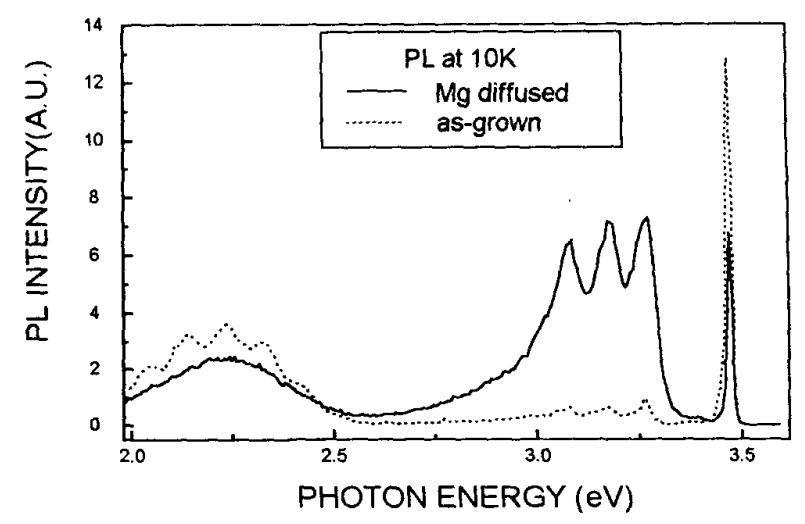

Figure 3. Typical PL spectra of as-grown (dash line) and $\mathrm{Mg}$ diffused (solid line) $\mathrm{GaN}$ samples at $10 \mathrm{~K}$. 